DOI: https://doi.org/10.24867/03AM07Vujicic

\title{
METODE OPTIMALNOG UPRAVLJANJA ZA OPTIMIZACIJU PERFORMANSI TRKAČKIH VOZILA
}

\section{OPTIMAL CONTROL METHODS FOR THE OPTIMIZATION OF RACE CAR PERFORMANCE}

\author{
Luka Vujičić, Fakultet tehničkih nauka, Novi Sad
}

\section{Oblast - MEHANIZACIJA I KONSTRUKCIONO MAŠINSTVO}

Kratak sadržaj - Razvijen je metod za simulaciju vremena kruga zasnovan na teoriji optimalnog upravljanja. Korišćen je kinematski model vozila sa jednim tragom. Problem je rě̌en metodom direktne kolokacije. Metodom je izvršena minimizacija vremena kruga sa istovremenom optimizacijom parametara.

Ključne reči: Teorija optimalnog upravljanja, Dinamika vozila, Optimizacija

Abstract - An optimal control lap time simulation method is developed. The vehicle model used is a kinematic single track model. The problem is solved with the direct collocation method. An example lap time minimisation study with simultaneous parameter optmization is performed..

Keywords: Optimal control theory, Vehicle dynamics, Optimization

\section{UVOD}

Osnovni kriterijum u razvoju u moto-sportu je izvršiti dati manevar za minimalno vreme. Pri tome fizičke granice trkačke staze i tehnička ograničenja definisana pravilima moraju da se poštuju. U granicama ovih pravila konstruktori i trkački timovi razvijaju i podešavaju vozila da minimizuju vreme kruga.

U ovom procesu se koriste simulacije da bi se ispitao uticaj konstrukcionih i parametera podešavanja na performanse vozila.

Oblasti razvoja uključuju generisanje aerodinamičke sile potiska, poboljšanje prijanjanja pneumatika, karakteristika pogonske grupe $\mathrm{i}$ oslanjanja $\mathrm{i} \mathrm{dr}$. U donošenju odluka inženjeri koriste tzv. alate za simulaciju vremena kruga da ispitaju uticaj ovih parametara na vreme kruga.

Pregled razvijenih metoda je dat $\mathrm{u}[1,2]$.

Cilj rada jeste razvoj metoda za optimizaciju performansi zasnovanog na optimalnom upravljanju. Metod treba da bude fleksibilan u smislu lakih izmena modela i daljeg razvoja metoda.

\section{NAPOMENA:}

Ovaj rad proistekao je iz master rada čiji mentor je bio dr Željko Kanović, vanr. prof.

\section{MODELOVANJE I FORMULACIJA PROBLEMA}

\subsection{Modelovanje staze}

Da bi se definisao manevar koji vozilo treba da izvrši potreban je matematički opis staze.

Za opis staze korišćen je kurvilinearni koordinatni sistem.

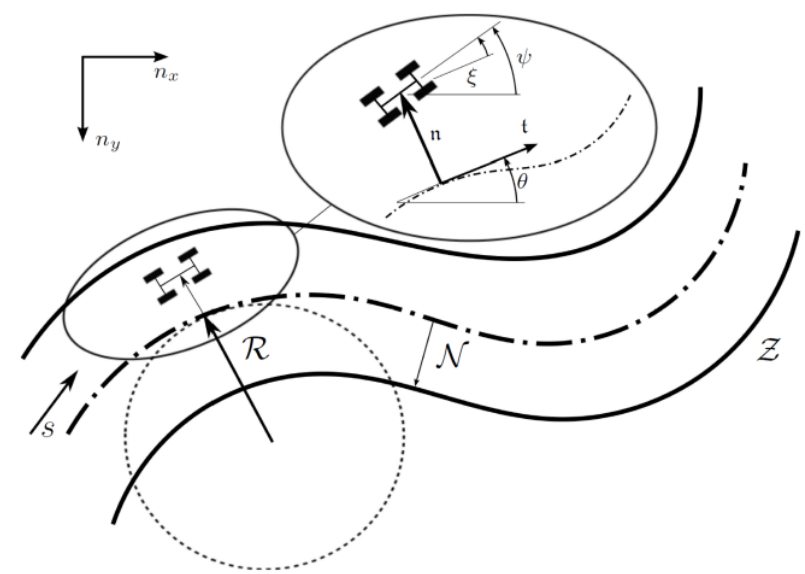

Slika 1. Kurvilinearni opis staze [3]

Kako je prikazano na slici 1., pozicija težišta je definisana kurvilinearnom apscisom $s(t)$ i vektorom $\boldsymbol{n}(s(t))$. Prva veličina jeste rastojanje pređeno srednjom linijom od startne linije, dok je druga rastojanje težišta vozila od srednje linije u pravcu normalnom na vektor tangente srednje linije $t(s(t))$.

Staza je u bilo kojoj tački $s$ opisana poluprečnikom krivine R, $C=1 / R$ i polu-širinom $N$. Vektor tangente srednje linije staze $\boldsymbol{t}$ definisan je uglom orijentacije staze $\theta$. Kako je $\xi$ ugao između podužne ose vozila i $\boldsymbol{t}$, apsolutni ugao zakretanja vozila je $\psi=\theta+\xi$.

Podrazumeva se da je pređeni put $s(t)$ funkcija vremena koja isključivo raste $\mathrm{i}$ da su, prema tome, rastojanje $\mathrm{i}$ vreme alternativne nezavisne promenljive.

Relacije između lokalnog koordinatnog sitema vozila i globalnog kurvilinearnog sistema date su sledećim jednačinama [3]:

$$
\begin{aligned}
& \frac{d s}{d t}=\frac{v \cos (\beta+\xi)}{1-n C} \\
& \frac{d n}{d t}=v \sin (\beta+\xi) \\
& \frac{d \xi}{d t}=\frac{d \psi}{d t}-C \frac{d s}{d t}
\end{aligned}
$$




\subsection{Modelovanje vozila}

Korišćen je kinematski model vozila sa jednim tragom [4]. Promenljive stanja i upravljačke promenljive su definisane redom vektorima stanja i upravljanja:

$$
\begin{gathered}
x=\left(\begin{array}{ccc}
v & \beta & \psi
\end{array}\right) \\
u=\left(\begin{array}{ll}
\delta & \mathrm{a}
\end{array}\right)
\end{gathered}
$$

gde je $v$ brzina težišta, $\beta$ ugao bočnog klizanja, $\psi$ ugao zakretanja vozila, $\delta$ ugao zakretanja upravljanog točka i $a$ ubrzanje težišta $u$ istom pravcu kao i brzina. Ove veličine su prikazane na slici 1.

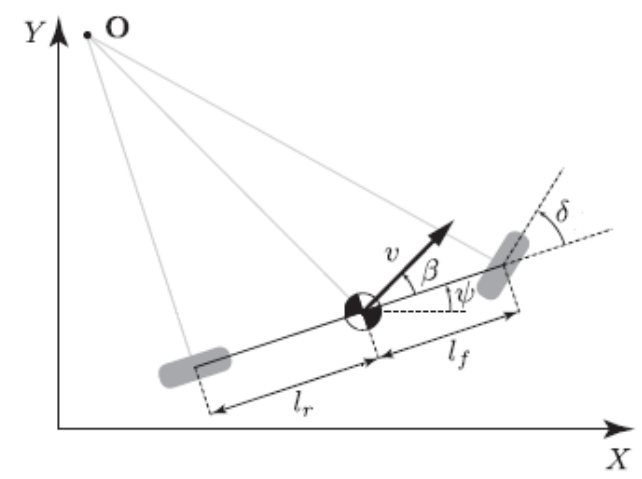

Slika 2. Kinematski model vozila sa jednim tragom [4] Jednačine koje opisuju model su:

$$
\begin{gathered}
\frac{d v}{d t}=a \\
\frac{d \beta}{d t}=\tan ^{-1}\left(\frac{l_{r}}{l_{r}+l_{f}} \tan \delta\right) \\
\frac{d \psi}{d t}=\frac{v}{l_{r}} \sin \beta
\end{gathered}
$$

Parametri modela su rastojanje težista od prednje i zadnje osovine, redom $l_{f}$ i $l_{r}$.

Pri simulaciji dinamičkih sistema kao nezavisna promenljiva se obično koristi vreme. Međutim u ovom slučaju, vreme i pređeni put se mogu smatrati alternativnim nezavisnim promenljivim. Za ovu primenu, korišćenje pređenog puta kao nezavisne promenljive ima prednosti. Naime, uspostavlja se eksplicitna veza sa pozicijom vozila na stazi i smanjuje konačna veličina problema. Promena nezavisne promenljive se može izvršiti samo ako postoji tačna korespondencija između $s$ i $t$. Ovo je tačno samo ako se vozilo kreće samo u pravcu rasta $s$. Faktor za promenu je recipročna vrednost brzine duž srednje linije staze[3] :

$$
S_{f}=\left(\frac{d s}{d t}\right)^{-1}=\frac{1-n C}{v(s) \cos (\beta(s)+\xi(s))}
$$

Ovom promenom uvodimo i dva nova stanja, normalno rastojanje od srednje linije $n$ i ugao između podužne ose vozila i tangente srednje linije staze $\xi$.

Izvodi stanja po pređenom putu dobijaju se pomoću jednačina $(2,3,6,7,8)$, tako sto se iste pomnože faktorom $S_{f}$ :

$$
\begin{aligned}
& \frac{d n}{d s}=\frac{d n}{d t} S_{f} \\
& \frac{d \xi}{d s}=\frac{d \xi}{d t} S_{f} \\
& \frac{d v}{d s}=\frac{d v}{d t} S_{f}
\end{aligned}
$$

$$
\begin{aligned}
& \frac{d \beta}{d s}=\frac{d \beta}{d t} S_{f} \\
& \frac{d \psi}{d s}=\frac{d \psi}{d t} S_{f}
\end{aligned}
$$

\subsection{Formulacija problema optimalnog upravljanja}

Cilj ovog metoda jeste da se pronađu optimalne putanje stanja i kontrola dinamičkog sistema (trkačko vozilo) za koje je vreme manevra minimalno. Pri tome se moraju poštovati ograničenja dinamike vozila, ograničenja staze i ograničenja vrednosti promenljivih stanja i upravljanja. Ovi zahtevi su formulisani u sledeći problem optimalnog upravljanja:

$$
\begin{gathered}
\min \quad J=\int_{s_{0}}^{s_{f}} \frac{1-n(s) C(s)}{v(s) \cos (\beta(s)+\xi(s))} d s \\
\text { s.t. } \quad \frac{d x}{d s}=f(x(s), u(s)) \\
x\left(s_{0}\right)=x_{0} \\
\quad x\left(s_{f}\right)=x_{f} \\
x_{L} \leq x(s) \leq x_{U} \\
u_{L} \leq u(s) \leq u_{U} \\
N_{l} \leq n(s) \leq N_{r}
\end{gathered}
$$

Funkcija cilja $J$ jeste minimizacija vremena manevra. Jednačina (16) definiše ograničenja dinamike vozila. Ograničenja početnog i krajnjeg stanja su definisana jednačinama $(17,18)$. Jednačine $(19,20)$ su ograničenja vrednosti promenljivih stanja i upravljanja, gde indeksi ${ }_{L} i$ u označavaju donje i gornje granične vrednosti koje se mogu odrediti na osnovu poznavanja dinamičkog sistema. $\mathrm{Na}$ kraju, vozilo se zadržava u okviru granica staze ograničenjem definisanim jednačinom (21), gde su $N_{l}$ i $N_{r}$ leva i desna polu-širina staze.

\subsection{Rešavanje problema optimalnog upravljanja}

Izabrani numerički metod rešavanja je direktna kolokacija [5], u kojoj se kontinualni problem optimalnog upravljanja pretvara u diskretni nelinearni program.

Interval pređenog puta na kom je problem definisan [sO...sf] je diskretizovan u $N$ segmenata:

$$
s_{0}=s_{1}<s_{2} \ldots<s_{N}=s_{F}
$$

Diskretni korak $h_{i}$ je definisan sledećom jednačinom:

$$
h_{i}=s_{i+1}-s_{i} \quad \text { za } i=1 \ldots N-1
$$

Sada kada je problem diskretizovan formuliše se nelinearni program:

$$
\begin{gathered}
\min \quad J=\sum_{i=1}^{N-1} \frac{h_{i}}{2}\left(S_{f i}+S_{f i+1}\right) \\
\Phi_{i}=x i+1-x i-\frac{h i}{2}\left(x_{i}^{\prime}+x_{i+1}^{\prime}\right)=0 \quad \text { za } i=1 \ldots N-1 \\
\Upsilon=x_{N}-x_{f}=0 \\
\Psi=x_{1}-x_{0}=0 \\
\square \\
t_{l} \leq n(s) \leq t_{r} \\
x_{L} \leq x(s) \leq x_{U} \\
u_{L} \leq u(s) \leq u_{U}
\end{gathered}
$$


Funkcija cilja $J$ definisana je primenom trapezoidnog pravila numeričke integracije na integral recipročne vrednosti brzine duž srednje linije staze $S_{f}$ u granicama u kojim je problem definisan. Isto pravilo numeričke integracije je primenjeno u ograničenju dinamike sistema $\Phi$, gde x' predstavlja jednačine (10-14).

Ograničenja u jednačinama (26-30) predstavljaju diskretizovana ograničenja problema optimalnog upravljanja koja su definisana jednačinama (17-21).

\subsection{Implementacija}

Implementacija metoda je izvršena u programskom jeziku Julia [6], koristeći jezik za algebarsko modelovanje JuMP [7]. Za rešavanje konačnog nelinearnog programa korišćen je solver IPOPT [8]. Prvi i drugi izvodi potrebni za formiranje Jakobijeve i Heseove matrice koje IPOPT zahteva kao ulaz izračunati su metodom algebarske diferencijacije koja je deo paketa JuMP.

Prednost korišćenja ovog okruženja je to što je sve od modelovanja vozila, preko formulacije i transkripcije problema optimalnog upravljanja do rešavanja rezultujućeg nelinearnog programa urađeno $\mathrm{u}$ istom programskom jeziku. Ovo olakšava i ubrzava implementaciju metoda. Dodatne prednosti su performanse programskog jezika i činjenica da je sav korišćen softver otvorenog tipa (open source).

\section{REZULTATI SIMULACIJA}

\subsection{Minimalno vreme kruga}

Prva studija je minimizacija vremena manevra za ceo krug staze. Korišćena staza je prikazana na slici 3.a. Dužina staze je 1792[m], sa konstantnom širinom od 6 [m] celom dužinom staze i vozi se u smeru kazaljke na satu. Problemu su dodata dodatna ograničenja na količinu promene upravljačkih promenljivih između dva koraka. Parametri modela i informacije o rešenju su prikazani u tabelama 2. i 3. u dodatku.
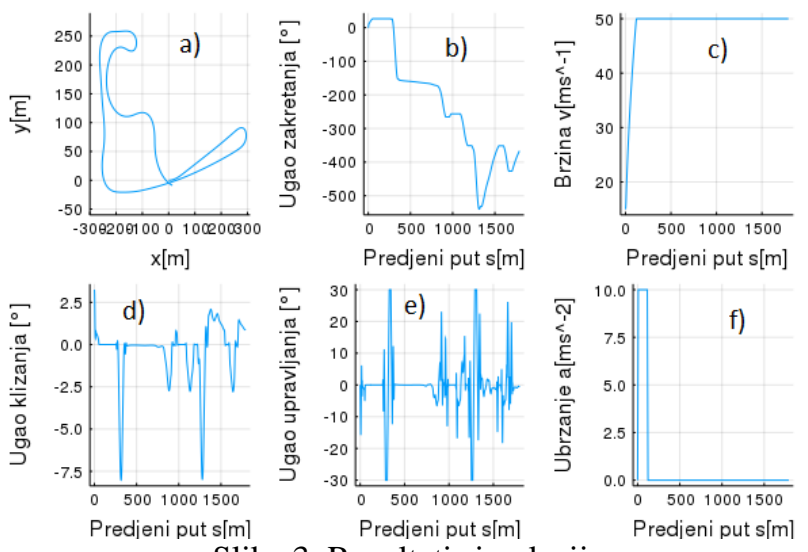

Slika 3. Rezultati simulacije

$\mathrm{Na}$ ostalim dijagramima na slici 3. prikazana su stanja i upravljačke promenljive. Može se videti da brzina počinje od zadate početnje vrednosti $0\left[\mathrm{~ms}^{-1}\right]$ i raste do $50\left[\mathrm{~ms}^{-1}\right]$, što je zadata gornja granična vrednost, na kojoj ostaje do kraja manevra. Ubrzanje takođe kreće od zadate početne vrednosti od $0\left[\mathrm{~ms}^{-2}\right]$ i raste do $10\left[\mathrm{~ms}^{-2}\right]$, dok brzina ne dostigne gornju graničnu vrednost, kada opet opada na 0 $\left[\mathrm{ms}^{-2}\right]$. Može se videti da ubrzanje ni u jednom trenutku ne dostiže negativnu vrednost $\mathrm{i}$ da kao posledica toga brzina ne opada.
Sistem se ovako ponaša zbog značajno pojednostavljenog modela vozila koji ne predstavlja verno ponašanje stvarnog vozila. Naime, model ne uzima u obzir sile koje deluju na vozilo, među njima i sile koje generišu pneumatici u kontaktu sa podlogom. Upravo ove sile ograničavaju bočno ubrzanje, a time i brzinu koju vozilo može da postigne u krivinama.

Ovo se odražava i na proračunatu putanju vozila koja je prikazana za jedan segment staze crnom linijom na slici 4. Vozilo ulazi u ovaj segment iz šikane desno-levo na unutrašnjoj strani i prelazi na unutrašnju stranu za sledeću desnu krivinu. Istu unutrašnju liniju zadržava i za sledeću desnu lakat krivinu, nakon čega prelazi na unutrašnju liniju za sledeću dugu levu krivinu, koja je poslednji deo ovog segmenta. Celom dužinom staze vozilo teži unutrašnjim linijama u krivinama, koje zadržava i na pravcima. Razlog za ovo jeste što vozilo brzo dostigne maksimalnu brzinu, nakon čega traži najkraću putanju unutar granica staze.

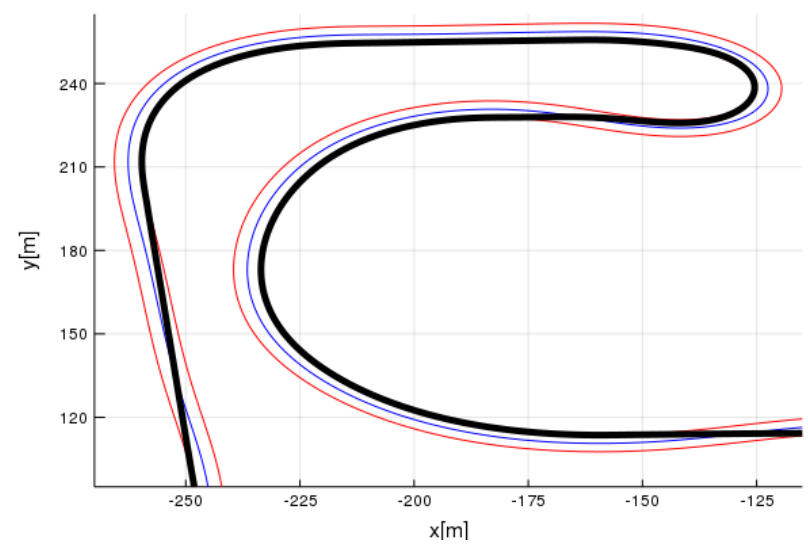

Slika 4. Optimalna putanja vozila za jedan segment staze

\subsection{Istovremena optimizacija parametara}

Prethodna studija je proširena istovremenom optimizacijom parametara. Za ovu studiju model je blago izmenjen. Osnovni model ima dva parametra $l_{f}$ i $l_{r}$. Za ovu studiju ova dva parametra su zamenjena jednim, raspodelom mase na prednjoj osovini $d_{f}$ i konstantom $l=l_{f}+l_{r}$, koja predstavlja ukupno osovinsko rastojanje. U jednačinama modela vozila $l_{f}$ i $l_{r}$ su zamenjeni sledećim izrazima:

$$
\begin{gathered}
l_{f}=\left(1-d_{f}\right) l \\
l_{r}=d_{f} l
\end{gathered}
$$

Osnovni problem optimalnog upravljanja je proširen jednostavno dodajući $d_{f}$ u promenljive i dva dodatna ograničenja, jedno za jednakost parametra u svim koracima i drugo za granične vrednosti parametra:

$$
\begin{gathered}
d_{f}\left(s_{i}\right)=d_{f}\left(s_{i+1}\right) \quad \text { za } i=1 \ldots N-1 \\
d_{f \min } \leq d_{f}(s) \leq d_{f \max }
\end{gathered}
$$

Rezultati ove studije u poređenju sa prvom dati su u tabeli 1 .

Tabela 1. Rezultati optimizacije parametara

\begin{tabular}{|c|c|c|}
\cline { 2 - 3 } \multicolumn{1}{c|}{} & Osnovno & Optimizovano \\
\hline Vreme kruga [s] & 36.2784 & 36.2779 \\
\hline$d_{f}[-]$ & 0.48 & 0.401 \\
\hline$l_{f}[\mathrm{~m}]$ & 1.716 & 1.976 \\
\hline$l_{r}[\mathrm{~m}]$ & 1.584 & 1.323 \\
\hline
\end{tabular}




\section{ZAKLJUČAK}

$\mathrm{Na}$ osnovu gore prezentovanog rada se mogu izvesti sledeći zaključci:

- Kinematski model vozila za jednim tragom korišćen u radu je jednostavan za implementaciju i parametrizaciju sa samo dva parametra. Takođe, metod sa ovim modelom pokazuje dobru efikasnost. Međutim model je previše pojednostavljen, što je pokazano i naglašeno u rezultatima simulacija koji ne reprodukuju ponašanje stvarnog vozila

- Izbor metoda direktne kolokacije za numeričko rešavanje problema optimalo upravljanja se pokazao kao dobar. Metod se pokazao kao robustan i fleksibilan, što je pokazano jednostavnom izmenom modela i problema za omogućenje istovremene optimizacije parametara

- Okruženje u kom je izvršena implementacija metoda se pokazala dobro. Ceo metod je implementovan u programskom jeziku Julia. Paket za optimizaciju JuMP je moćan sa svojom funcionalnošću algoritamske diferencijacije, koja nije pre korišćena za ovu primenu

Kao pravac daljeg istraživanja i razvoja metoda prioritet ima model vozila, kako bi metod mogao da uvid u optimalno ponašanje stvarnog vozila. Predlaže se korišćenje dinamičkog modela sa nelinearnim modelom pneumatika. Korisno bi bilo i istražiti uticaj složenosti modela na efikasnost metoda, odnosno vremena proračuna.

\section{DODATAK}

Tabela 2. Parametri modela i simulacije

\begin{tabular}{|c|c|c|}
\hline Simbol & Opis & Jedinica \\
\hline$l_{f}[\mathrm{~m}]$ & $\begin{array}{c}\text { Rastojanje težišta od prednje } \\
\text { osovine }\end{array}$ & 1.72 \\
\hline$l_{r}[\mathrm{~m}]$ & $\begin{array}{c}\text { Rastojanje težišta od zadnje } \\
\text { osovine }\end{array}$ & 1.58 \\
\hline$v_{\max }\left[\mathrm{ms}^{-1}\right]$ & $\begin{array}{c}\text { Gornja granična vrednost } \\
\text { brzine }\end{array}$ & 50 \\
\hline$a_{\max }\left[\mathrm{ms}^{-1}\right]$ & $\begin{array}{c}\text { Gornja granična vrednost } \\
\text { ubrzanja }\end{array}$ & 10 \\
\hline$\delta_{\min }\left[{ }^{\circ}\right]$ & $\begin{array}{c}\text { Donja granična vrednost } \\
\text { ugla upravljanja }\end{array}$ & -30 \\
\hline$\delta_{\max }[\circ]$ & $\begin{array}{c}\text { Gornja granična vrednost } \\
\text { ugla upravljanja }\end{array}$ & 30 \\
\hline$r_{a}\left[\frac{m s^{-2}}{k o r a k}\right]$ & Količina promene ubrzanja & 1 \\
\hline$r_{b}\left[\frac{\circ}{\text { korak }}\right]$ & $\begin{array}{c}\text { Količina promene ugla } \\
\text { upravljanja }\end{array}$ & 2 \\
\hline$v_{0}\left[\mathrm{~ms}^{-1}\right]$ & Početna brzina & 15 \\
\hline$\psi_{0}\left[{ }^{\circ}\right]$ & Početni ugao zakretanja & 0 \\
\hline$a_{0}\left[\mathrm{~ms}^{-2}\right]$ & Početno ubrzanje & 0 \\
\hline$\delta_{0}\left[{ }^{\circ}\right]$ & Početni ugao upravljanja & 0 \\
\hline
\end{tabular}

Tabela 3. Informacije o rešenju prve studije

\begin{tabular}{|c|c|c|}
\hline Opis & Vrednost & Jedinica \\
\hline Diskretni korak $h$ & 0.8 & $\mathrm{~m}$ \\
\hline $\begin{array}{c}\text { Broj diskretnih tačaka } \\
\text { Broj promenljivih nelinearnog } \\
\text { programa }\end{array}$ & 2240 & - \\
\hline Trajanje proračuna & 33.6 & $\mathrm{~s}$ \\
\hline
\end{tabular}

\section{LITERATURA}

[1] D. Casanova, "On minimum time manouvering: The theoretical optimal lap", $\mathrm{PhD}$ Thesis, Cranfield University, 2000.

[2] T. Völkl, "Erweiterte quasistatische Simulation zur Bestimmung des Einflusses transienten Fahrzeugverhaltens auf die Rundenzeit von Rennfahrzeugen", PhD Thesis, Tehnische Universität Darmstadt, 2013.

[3] G. Perantoni, D.J.N. Limebeer, "Optimal control for a formula one car with variable parameters", Vehicle System Dynamics, Vol. 52, pp. 653-678, September 2014.

[4] J. Kong, M. Pfeiffer, G. Schildbach. F. Borrelli, "Kinematic and Dynamic Vehicle Models for Autonomous Driving Control Design", IEEE Inteligent Vehicles Symposium, 2015

[5] J.T. Betts, "Practical Methods for Optimal Control and Estimation using Nonlinear Programming: Second Edition, Advances in Design and Control", Society for Industrial and Applied Mathematics, 2010.

[6] J. Bezanson, A. Edelman, S. Karpinski, V. Shah, "Julia: A Fresh Approach to Numerical Computing", SIAM Review, Vol. 59, pp. 65-98, 2017.

[7] I. Dunning, J. Huchette, M. Lubin, “JuMP: A modeling language for Mathematical Optimization", SIAM Review, Vol. 59, pp. 295-320, 2017.

[8] A. Wächter, L.T. Biegler, “On the Implementation of a Primal-dual Interior Point Filter Line Search Algorithm for Large-scale Nonlinear Programming", Mathematical Programming, Vol. 106, pp. 25-57, 2006.

\section{Kratka biografija:}

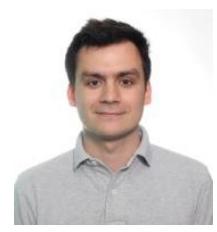

Luka Vujičić rođen je u Novom Sadu 1992. god. Master rad na Fakultetu tehničkih nauka iz oblasti Mehanizacije i konstrukcionog mašinstva - Automobilsko inženjerstvo odbranio je 2018.god.

kontakt: luka.vujicic@gmail.com 